\title{
Partial fetotomy: technique to resolve wry neck dystocia in mare
}

\author{
Mubbashar Hassan ${ }^{1, *}$, Sana Shahid ${ }^{1}$, Akhtar Rasool Asif ${ }^{1}$, Muhammad Ilyas Naveed ${ }^{1}$, Abid Hussain \\ Shahzad ${ }^{1}$ and Mumtaz Ali Khan ${ }^{2}$ \\ ${ }^{1}$ Department of Clinical Sciences, College of Veterinary and Animal Sciences (sub campus UVAS, Lahore), Jhang 35200, \\ Pakistan \\ ${ }^{2}$ Civil Veterinary Hospital Takht Bai, Mardan, Department of Livestock \& Dairy Development, Khyber Pakhtun Khwa 28441, \\ Pakistan
}

Received September 23, 2020

Revised December 5, 2020

Accepted December 7, 2020

\section{*Correspondence}

Mubbashar Hassan

E-mail: mubbashar.hassan@uvas.edu.pk

ORCID

https://orcid.org/0000-0003-0433-2697

\begin{abstract}
Foaling is a process of giving birth to foal which is prompt and forceful event in equine breeding. Dystocia is declared when 2nd stage of parturition exceeds from 20 min without fetal movements in mare. Dystocia is very challenging situation for both mare and veterinarian. Survivability of mare and foal, and subsequent fertility of mare depends on efficient management. Therefore, the current report described a rare case of wry neck (torticollis or unilateral bent neck) resulted in dystocia, that was efficiently resolved by partial fetotomy and repulsion technique in mare under field conditions. Intensive post operative care was performed to avoid infection and to achieve fertility subsequently.
\end{abstract}

Keywords: dystocia, mare, wry neck

\section{INTRODUCTION}

Horse-human interaction varied from centuries depending on the need of humans. Horse-human affiliation was greatest due to its strength to carry and pull load, and swiftness of humans mobility (Clutton-Brock, 1992). Horse usage for farm work and transport decreased in developed countries during the last forty years (Robinson, 1999). Breeder's interest is increasing to keep horse for leisure, hobbies for riding, tent pegging, dancing, derby, breeding, sale and purchase of excellent genetic foals. The biggest bottleneck is to yield viable and healthy foal from conception to birth during pregnancy (Ensminger, 1990).

Foaling is a process of giving birth to foal which is prompt and forceful event in equine breeding (Thanga- mani et al., 2018). Dystocia is declared when 2nd stage of parturition that exceeds from 20 min without fetal movements in mare (Frazer, 2009). Mare and foal morbidity, mortality and future fertility depend on time and decision made during foaling (Freeman et al., 1999). Dystocia is rare in mare compared to other domestic animals. Limitation is that its occurrence is $4 \%$ in thoroughbred (Morrow, 1986) and causes a challenging condition to many equine practitioners (Purohit, 2011). Dystocia is caused by maternal or fetal factors, among which fetal causes are most common in all animals (Threlfall, 2007). Fetal factors includes malpresentation (24\%), malposition (30\%) and malposture (86\%). Moreover, dystocia occurred in anterior (99\%), posterior $(0.9 \%)$ and transverse $(0.1 \%)$ presentation in mare (Frazer et al., 1997). Malposture of long fetal extremities such as limbs, head, and neck of fetus in uterus 
are the main factors for fetal dystocia (Frazer et al., 1997). Abnormality or delay during foaling prone to dystocia is very challenging situation for both mare and veterinarian (Purohit, 2011). Survivability of mare and foal, and subsequent fertility of mare depends on efficient management (Pynn, 2014). Different procedure are used to resolve dystocia in different farm animals and mare, including rotation, repulsion, traction, caesarean section and fetotomy of foal (Frazer, 2007).

Fetotomy is classified as partial and complete. $80 \%$ of dystocia cases are resolved through partial fetotomy in mare (Vandeplassche, 1987). Longer birth canal and swiftly detachment of fetal membranes make fetotomy more difficult in mares compared to cows (Frazer, 2007). Resection of one part or more in fetus is used to resolve dystocia if posture of head, neck and limb are abnormal (Frazer, 1997). Therefore, the current report describes a rare case of wry neck (torticollis or unilateral bent neck) resulted in dystocia, that was efficiently resolved by partial fetotomy and repulsion technique in mare under field conditions.

\section{CLINICAL CASE}

A five-year old, white, desi mare, weighing $500-550 \mathrm{~kg}$, having full term pregnancy during third parity was presented to extension services of College of Veterinary and Animal Sciences Jhang, with the history of straining form last five hr. Mare had thrown the first water bag three hr ago.

General clinical examination revealed $38.6^{\circ} \mathrm{C}$ of body temperature $44-46$ of heart beats and $24-30 / \mathrm{min}$ of respiratory rate. The animal was in right lateral recumbency with immoderate straining. Perineum was washed with povidone-iodine scrub and then rinsed with clean water.
Epidural anesthesia with $5 \mathrm{~mL}$ of $2 \%$ lignocaine hydrochloride was conducted to reduce the straining.

Vaginal examination was performed with lubricated plastic sleeves to assess the presentation, position and posture of the foal. On vaginal examination, fetus was found dead without showing any reflex having anterior longitudinal presentation, dorsosacral position with deviation of head and neck on right side and flexion of forelimbs beneath the body. Examiner tried to correct the posture manually and found the neck torticollis (stiff, wry neck) and fore and hindlimbs overlapped. Considering all these conditions, it was decided to resolve dystocia by partial fetotomy. Forelimbs were separated by applying resection on the knee joint of foal. Amputated foal legs were removed by traction. Following fetotomy, the foal was repelled in the uterus. Obstetrical chains were applied on hind limbs. Liquid paraffin was used continuously for lubrication during this process. Torticollis neck was made straight in front of the birth canal and removed by traction as shown in Fig.1A.

Antibiotic (Penivet-5, Benzyl Penicillin Procaine Penicillin G Streptomycin Sulphate Star Laborites Pvt, Pakistan) was administered for five days to cope up the infection. Supportive therapy (Ringer's Lactate) was performed to hydrate the mare and referred to the common veterinarian for medical follow-up. Anti-tetanus toxoid was also administered as shown in Fig. 1B. Mare was healthy and conceived in the next breeding season narrated by the owner on telephonic follow up.

\section{DISCUSSION}

To the best of my knowledge this is the first report in mare dystocia resolved through partial fetotomy performed during field condition in Desi mares. Dystocia
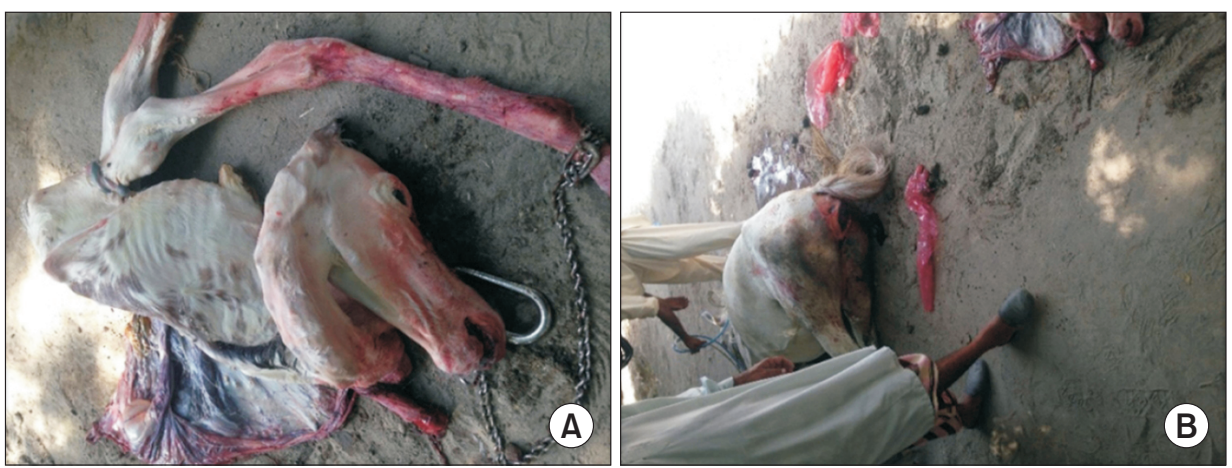

Fig. 1. (A) Wry neck foal after resolving dystocia (B) mare for post-operative treatment. 
is declared when 2 nd stage of parturition that exceeds from 20 min without fetal movements in mare (Frazer, 2009). Deviation of head and neck is the major cause of dystocia resulted in worse condition. This condition can be prevented by application of rope on the head of the foal before manipulation. Two type of deviations of head and neck such as ventral and lateral among which lateral deviation is extremely difficult to correct. Wry neck is proved to be the most difficult and rewarding conditions for mare dystocia (Pynn, 2014).

Equine dystocia is resolved through different techniques which include assisted vaginal delivery (rotation, repulsion and traction) in recumbent or standing mare and controlled vaginal delivery (caesarean section and fetotomy) (Frazer, 2007). Manipulation decision depends on foal status, economic value of both mare and foal, duration and severity of dystocia and clinician expertise. Foal viability is the prime consideration for making decision for adaptation of obstetrical procedure. One or two partial cut mostly resolve dystocia in live foal (Frazer et al., 1997) but for dead foal, fetotomy is preferred by skilled person because this condition is most challenging and hazardous for mare life (Higgins and Wright, 1999). Fetotomy is classified as partial and complete fetotomy. Earlier studies reported that partial fetotomy shorten the duration of intervention for delivery of a non viable fetus (Nimmo et al., 2007). During fetotomy, cuts are important for resolving dystocia. Previous studies reported 57\% cases of dystocia were resolved by one or two cuts and $21 \%$ cases were resolved by three fetotomy cuts (Frazer, 1997). Previous studies found $95.8 \%$ survival of mare after dystocia through fetotomy (Carluccio et al., 2007). In another report, $80 \%$ of dystocia cases are resolved by partial fetotomy technique in mare (Vandeplassche, 1987). Fetotomy is more difficult in mare compared to cow due to longer birth cavity and faster separation of placental membranes (Frazer, 2007). Dystocia due to postural defects of head and neck is efficiently resolved by applying one or two fetotomy cuts (Frazer, 1997). In the present report, dystocia was resolved by applying partial fetotomy technique. Forelimbs were separated by applying cuts on the knee joint of foal. Amputated foal legs were removed by traction. Following fetotomy foal was repelled in the uterus. Obstetrical chains were applied on hind limbs. Liquid paraffin was used for lubrication during this process. After resolving for post operative care antibiotic was recommended for five days to cope up the infection. This technique is cheap and easy than cesarian section in this type of rare cases of dystocia in mare.

\section{CONCLUSION}

It is concluded that by partial fetotomy followed by repulsion are the safe and practical solution to resolve dystocia during field condition. Furthermore, this technique is comparatively economical to handle emergency cases as compared to cesarean section, better recovery can be achieved by proper postoperative care.

\section{CONFLICTS OF INTEREST}

No potential conflict of interest relevant to this article was reported.

\section{AUTHOR CONTRIBUTIONS}

M Hassan and AR Asif performed this procedure on mare. M Hassan and S Shahid wrote the initial draft. MI Naveed, AH Shahzad and MA Khan help in critically reviewing this draft.

\section{AUTHOR'S POSITION AND ORCID NO.}

\author{
M Hassan, Lecturer, \\ https://orcid.org/0000-0003-0433-2697 \\ S Shahid, DVM Student, \\ https://orcid.org/0000-0002-7492-1537 \\ AR Asif, Assistant Professor, \\ https://orcid.org/0000-0002-2367-9322 \\ MI Naveed, Lecturer, \\ https://orcid.org/0000-0002-9361-6917 \\ AH Shahzad, Associate Professor, \\ https://orcid.org/0000-0002-9442-0000 \\ MA Khan, Senior Veterinary Officer, \\ https://orcid.org/0000-0003-2044-6344
}

\section{REFERENCES}

Carluccio A, Contri A, Tosi U, De Amicis I, De Fanti C. 2007. Survival rate and short-term fertility rate associated with the use of fetotomy for resolution of dystocia in mares: 72 cases (1991-2005). J. Am. Vet. Med. Assoc. 230:1502-1505.

Clutton-Brock J. 1992. Horse power: a history of the horse and 
the donkey in human societies. Natural History Museum Publications, London, pp. 192.

Ensminger ME. 1990. Horses and horsemanship. 6th ed, Interstate Publishers, Danville, pp. 629.

Frazer GS. 1997. Review of the use of fetotomy to resolve dystocia in the mare. Proc. Am. Assoc. Equine Practnrs. 262-268.

Frazer GS. 2007. Dystocia and fetotomy. In: Samper JC, Pycock J, McKinnon AO (Eds.), Current Therapy in Equine Reproduction, Elsevier Saunders, St. Louis, pp. 417-434.

Frazer GS. 2009. Dystocia management on the farm. 15th SIVE Congress Proc. Annu. Meet. Italian Assoc. Equine Vet. 57-59

Frazer GS, Perkins NR, Blanchard TL, Orsini J, Threlfall WR. 1997. Prevalence of fetal maldispositions in equine referral hospital dystocias. Equine Vet. J. 29:111-116.

Freeman DE, Hungerford LL, Schaeffer D, Lock TF, Sertich PL, Baker GJ, Vaala WE, Johnston JK. 1999. Caesarean section and other methods for assisted delivery: comparison of effects on mare mortality and complications. Equine Vet. J. 31:203-207.
Higgins AJ and Wright IM. 1999. The equine manual. Saunders, London, pp. 1143.

Morrow DA. 1986. Current therapy in theriogenology: diagnosis, treatment and prevention of reproductive diseases in small and large animals. 2nd ed, Saunders, Philadelphia, pp. 694.

Purohit GN. 2011. Intra-partum conditions and their management in mare. J. Livest. Sci. 2:20-37.

Pynn O. 2014. Managing mare dystocia in the field. In Pract. 36:347-354.

Robinson IH. 1999. The human-horse relationship: how much do we know? Equine Vet. J. Suppl. (28):42-45.

Threlfall WR. 2007. Parturition and dystocia. In: Youngquist RS, Threlfall WR (Eds.), Current Therapy in Large Animal Theriogenology. 2nd ed, Saunders Elsevier, St. Louis, pp. 118130.

Vandeplassche MM. 1987. The pathogenesis of dystocia and fetal malformation in the horse. J. Reprod. Fertil. Suppl. 35:547-552. 